\title{
SINTESIS DAN KARAKTERISASI ZEOLIT FAUJASIT DARI LIMBAH BATUBARA OMBILIN DENGAN METODA ALKALI HIDROTERMAL AIR LAUT
}

\author{
Upita Septiani, Widya Yuliani Fatiha, SyukriArief \\ Laboratorium Kimia Material Jurusan Kimia FMIPA, Universitas Andalas Padang \\ e-mail: upitas@yahoo.com
}

\begin{abstract}
Zeolite synthesis using Ombilin coal fly ash at low temperature with alkaline hydrothermal process has been carried out. The used Fly ash was melted by $\mathrm{NaOH}$ at a temperature of $550^{\circ} \mathrm{C}$. Alkaline hydrothermal processes in zeolite synthesis performed with variations of temperature at $35^{\circ} \mathrm{C}, 45^{\circ} \mathrm{C}$ and $60^{\circ} \mathrm{C}$. The zeolite that obtained was characterized by using Fourier Transform Infra Red (FT - IR), X - Ray Diffraction (XRD) , Scanning Electron Microscopy (SEM) in combination with EDX . The characterization results showed the formation of zeolite were better when an increasing in temperature processes and the use of sea water as a solvent. On the use of seawater, were obtained sodalit zeolite with the chemical formula $\mathrm{Na}_{8}\left(\mathrm{Al}_{6} \mathrm{Si}_{6} \mathrm{O}_{24}\right) \mathrm{Cl}_{2}$.
\end{abstract}

Keywords: zeolite, fly ash, alkali hydrothermal,crystallization

\section{PENDAHULUAN}

Zeolit sintetik kelas Faujasit (FAU) terdiri dari zeolit tipe $\mathrm{NaX}, \mathrm{NaY}$ dan Linde $\mathrm{X}$ yang biasanya digunakan sebagai adsorben, penukar ion dan katalis. Selain itu, zeolit kelas faujasit ini juga dapat digunakan pada pemurnian gas alam dari gas sulfur dan $\mathrm{CO}_{2}$, untuk pengeringan minyak dan gas alam, dan sebagai agents pendingin dalam pemisahan campuran hidrokarbon. Saat ini, penelitian pada zeolit sintetik lebih difokuskan pada penggunaan material-material limbah dan murah sebagai bahan dasar dan penggunaan metode-metode modern yang efectif untuk mensintesanya.

Pembangkit Listrik Tenaga Uap (PLTU) Ombilin mengunakan batubara sebagai bahan bakarnya akan menghasilkan limbah gas seperti $\mathrm{CO}_{2}, \mathrm{SO}_{2}, \mathrm{NO}_{2}$, dan limbah padat yaitu fly ash dan bottom ash. Jumlah fly ash yang dihasilkan per harinya cukup besar yaitu sekitar 4000 ton $/$ hari $^{1,2}$. Hasil analisis $X$-ray Fluorescence (XRF) pada penelitian kami sebelumnya, fly ash dari PLTU Ombilin ini tersusun dari $51,8 \%$ silika $\left(\mathrm{SiO}_{2}\right), 26,9 \%$ alumina $\left(\mathrm{Al}_{2} \mathrm{O}_{3}\right), 0,7 \% \mathrm{MgO}, 2 \% \mathrm{CaO}$ dan
5,1\% $\quad \mathrm{Fe}_{2} \mathrm{O}_{3}$. Zeolit sintetik dengan kadar silika rendah $\mathrm{NaX}$ dan $\mathrm{NaY}$ dapat disintesa dari material dasar seperti fly ash.

Biasanya metode yang digunakan untuk mensintesa zeolit dari fly ash adalah metode hidrotermal dan metode alkali hidrotermal (Hydrothermal with a fusion pre-treatment) . Pada metode alkali hidrotermal, selain sumber material dasar (silika dan alumina), kondisi proses seperti; temperatur, $\mathrm{pH}$, jenis kation alkali, waktu reaksi maupun surfaktan sangat menentukan jenis, ukuran pori, ukuran partikel dan morfologi dari zeolit yang disintesa. Pada penelitian sebelumnya kami telah mensintesa zeolit $\mathrm{NaX}$ dari fly ash batubara Ombilin dengan metode alkali hidrotermal menggunakan air destilasi pada variasi temperatur rendah dengan masa inkubasi 4 hari.

Pada penelitian ini kami akan mensistesis zeolit kelas faujasit tipe $\mathrm{NaX}$ dari fly ash batubara Ombilin dengan metode alkali hidrotermal menggunakan air laut sebagai pelarutnya. Proses hidrotermal dilakukan pada variasi temperatur rendah yaitu 35,45 dan $60^{\circ} \mathrm{C}$ dengan waktu inkubasi selama 4 hari. Zeolit yang terbentuk dikarakterisasi 
dengan XRD, FT-IR dan SEM-EDX, kemudian hasil ini akan dibandingkan dengan hasil zeolit yang disintesa dengan proses hidrotermal menggunakan air destilasi sebagai pelarut (penelitian kami sebelumnya).

\section{METODOLOGI PENELITIAN}

\section{Bahan Kimia dan Peralatan}

Peralatan yang digunakan diantaranya adalah beberapa peralatan gelas, autoclave, ayakan, timbangan, oven, sentrifuge, lumpang, XRD (Philip X'pert Powder Type PW4030/60), SEM-EDX (Phenom Pro X), FT-IR (Perkin Elmer 1600 series). Bahan yang digunakan antara lain adalah fly ash batubara dari PLTU Ombilin, $\mathrm{NaOH}$ dan air laut dari pantai Padang.

\section{Prosedur Penelitian}

\section{Perlakuan untuk air laut}

Air laut yang digunakan diambil dari pantai Padang. Air laut ini diambil pada bagian tepi pantai, kemudian dilakukan penyaringan untuk memisahkan pengotor seperti pasir dan kotoran lainnya. Setelah dilakukan penyarinyan air laut disimpan di dalam wadah tertutup.

\section{Sintesa Zeolit}

Sintesa zeolite terdiri dari dua tahap, tahap peratama peleburan fly ash dengan $\mathrm{NaOH}$. Pada tahap ini 10 gram fly ash dan 12 gram $\mathrm{NaOH}$ dihaluskan menggunakan lumpang selama beberapa menit, kemudian dipanaskan pada temperatur $550^{\circ} \mathrm{C}$ selama 1 jam. Hasilnya didinginkan dan digiling kembali. Tahap kedua yaitu proses hidrotermal, Pada tahap ini bubuk hasil peleburan fly ash ditambah dengan $43 \mathrm{ml}$ air laut, dimasukan dalam autoclave untuk proses hidrotermal dengan variasi temperatur 35,45 dan $60^{\circ} \mathrm{C}$ dengan lama inkubasi 4 hari. Hasil proses hidrotermal tersebut dipisahkan bagian padatnya dengan sentrifugasi, dicuci dengan air destilasi, kemudian dikeringkan selama 12 jam pada temperatur $80^{\circ} \mathrm{C}$. Zeolit yang didapatkan dikarakterisasi dengan XRD, SEM-EDX dan FT-IR.

\section{HASIL DAN DISKUSI}

\section{Karakterisasi dengan FTIR}

Spektrum FT-IR memperlihatkan fasa padat alumiumsilikat setelah bereaksi pada variasi temperatur inkubasi $35^{\circ} \mathrm{C}, 45^{\circ} \mathrm{C}$ dan $60^{\circ} \mathrm{C}$.

Jika diamati dari gambar 1 maka dapat dilihat masing-masing memiliki pita serapan pada angka gelombang 3200-2550 cm $\mathrm{cm}^{-1}$ yang berhubungan dengan gugus hidroksil $(-\mathrm{OH})$ bonded, gugus ini dimungkinkan berasal dari air hidrat pada kristal.

Pita adsorban antara angkagelombang 980$1320 \mathrm{~cm}^{-1}$ menyatakan adanya atom $\mathrm{Al}$ tersubstitusi dalam bentuk tetrahedral dari kerangka silika. Pada angka gelombang tersebut menunjukkan adanya vibrasi rentangan $\mathrm{Si}-\mathrm{O}$ atau $\mathrm{Al}-\mathrm{O}$ dalam $\mathrm{SiO}_{4}$ atau $\mathrm{AlO}_{4}$ tetrahedral.

Untuk angka gelombang antara $650-750 \mathrm{~cm}^{-1}$ menunjukkan pita serapan untuk $\mathrm{Na}-\mathrm{X}$ (x untuk ikatan Si-O dan Al-O) zeolit. Pada gambar 3a, 3b dan $3 \mathrm{c}$ terlihat terlihat masingmasing 2 pita serapan yaitu antara $730 \mathrm{~cm}^{-1}$ $667 \mathrm{~cm}^{-1}$.

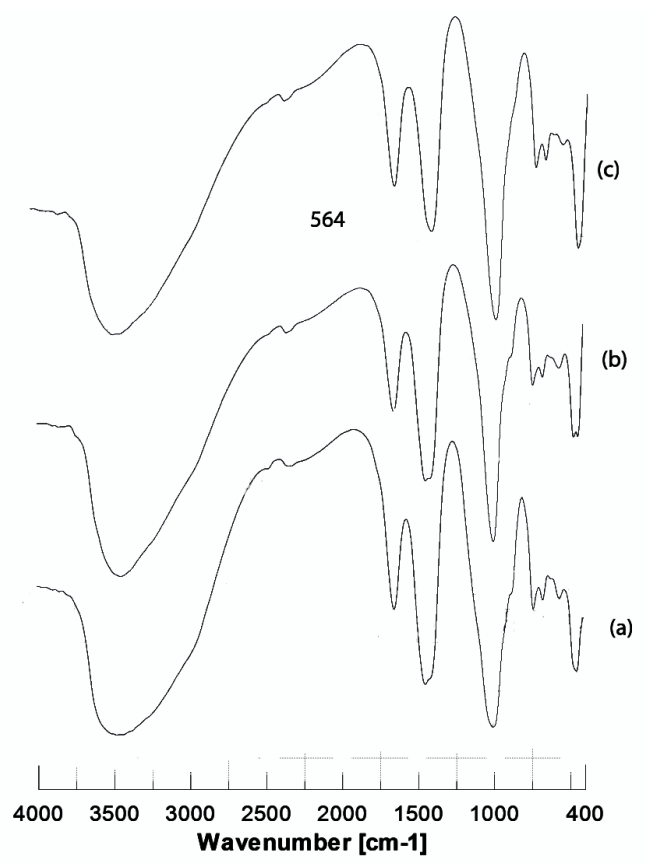

Gambar 1. Spektrum FTIR zeolit sintesis pada (a) suhu $35^{\circ} \mathrm{C}$, (b) pada suhu $45^{\circ} \mathrm{C}$, (c) pada suhu $60^{\circ} \mathrm{C}$. 
Jika diamati dari Gambar 1 maka dapat dilihat masing-masing memiliki pita serapan pada angka gelombang $3200-2550 \mathrm{~cm}^{-1}$ yang berhubungan dengan gugus hidroksil $(-\mathrm{OH})$ bonded, gugus ini dimungkinkan berasal dari air hidrat pada kristal.

Pita adsorban antara angkagelombang 980$1320 \mathrm{~cm}^{-1}$ menyatakan adanya atom Al tersubstitusi dalam bentuk tetrahedral dari kerangka silika. Pada angka gelombang tersebut menunjukkan adanya vibrasi rentangan $\mathrm{Si}-\mathrm{O}$ atau Al-O dalam $\mathrm{SiO}_{4}$ atau $\mathrm{AlO}_{4}$ tetrahedral.

Untuk angka gelombang antara $650-750 \mathrm{~cm}^{-1}$ menunjukkan pita serapan untuk Na-X (x untuk ikatan Si-O dan Al-O) zeolit. Pada gambar 3a, 3b dan 3c terlihat terlihat masingmasing 2 pita serapan yaitu antara $730 \mathrm{~cm}^{-1}$ $667 \mathrm{~cm}^{-1}$.

\section{Karakterisasi dengan XRD}

Analisis XRD dilakukan untuk mengetahui senyawa atau kristal yang terbentuk dalam suatu material kristalin sehingga akan diketahui struktur, orientasi, dan ukuran kristal. Dari pola difraksi sinar-X pada gambar dapat dilihat bahwa hasil sintesis menunjukkan terbentuknya sodalit pada kristalisasi.

Dari pola difraksi yang terlihat pada Gambar 2 diatas kita dapat melihat bahwa pada saat peningkatan suhu dalam proses alkali hidrotermal terjadi juga peningkatan intensitas puncaknya yang menandakan bahwa kristal zeolit juga semakin baik saat suhu proses alkali hidrotermal ditingkatkan. Lebih lanjut, jika diamati terlihat intensitas semakin baik dan semakin tinggi jika menggunakan air laut, dimana pada penggunaan air laut dalam proses alkali hidrotermal ini memperlihatkan terbentuknya sodalit yang merupakan kerangka dari zeolit tipe X.

Dapat dilihat penggunaan air laut dalam proses alkali hidrotermal pada suhu rendah memperlihatkan bahwa pada penggunaan air laut terdapat puncak tertinggi yaitu pada $2 \theta$ 24,43 yang merupakan puncak untuk Sodalit (JCPDS 01-074-3647).

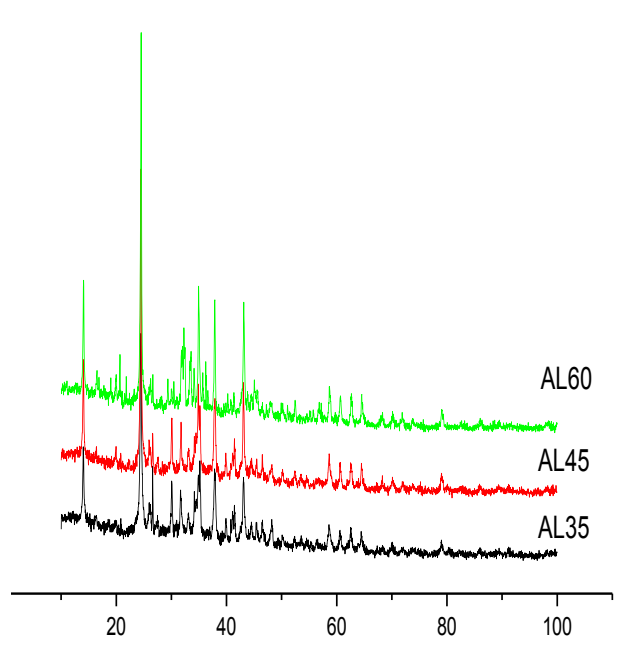

Gambar 2. Hasil XRD zeolit sintesis dengan proses hidrotermal air laut, AL 35 pada suhu $35^{\circ} \mathrm{C}$, AL 45 pada suhu $45^{\circ} \mathrm{C}$ dan $\mathrm{AL} 60$ pada suhu $60^{\circ} \mathrm{C}$.

\section{Karakterisasi dengan SEM-EDX}

Analisis mikrostruktur dilakukan dengan menggunakan SEM yang bertujuan untuk melihat morfologi permukaan. Pada prinsipnya, analisis permukaan melibatkan radiasi permukaan dengan sumber energi yang cukup untuk menembus dan menimbulkan beberapa transisi yang menghasilkan emisi dari permukaan berkas energi yang bias dianalisis.

Dari gambar hasil SEM dapat dilihat penggunaan air laut saat adanya peningkatan suhu yang digunakan maka bentuk partikel dan morfologi kristalnya semakin jelas. Ini membuktikan bahwa bentuk partikelnya semakin baik sehingga agregasi yang dihasilkan juga meningkat.

Sementara itu, untuk mengetahui komposisi dari unsur-unsur yang ada di dalamnya dapat digunakan EDX. Pada prinsipnya SEM-EDX merupakan system analisis yang menggabungkan SEM dan EDX kedalam satu unit yang dirancang pada konsep pengembangan produk sehingga memungkinkan analisis untuk mencapai pengamatan cepat, jelas dan akurat. Data EDX dari hasil penelitian yang telah dilakukan dapat dilihat dari Tabel 1 untuk air destilasi. 
a

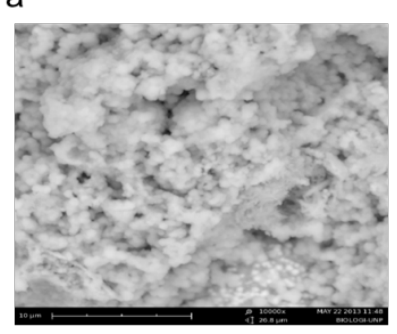

b

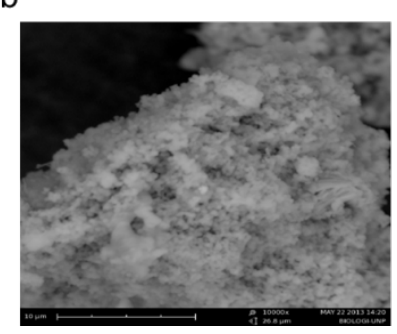

C

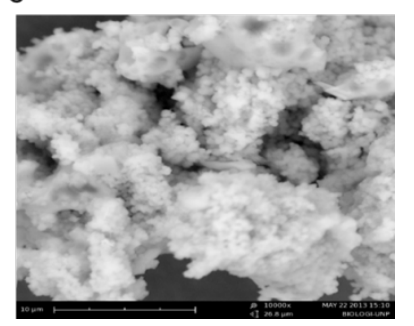

Gambar 3. Hasil Karakterisasi SEM zeolit sintesis pada perbesaran 10.000x. a) Zeolit sintesis dengan pada suhu $35^{\circ} \mathrm{C}$. b) Zeolit sintesis dengan pada suhu $45^{\circ} \mathrm{C}$. c) Zeolit sintesis dengan pada suhu $60^{\circ} \mathrm{C}$.

Tabel 1. Data EDX sintesa zeolit dengan proses hidrotermah menggunakan air laut

\begin{tabular}{cccc}
\hline \multirow{2}{*}{ unsur } & \multicolumn{3}{c}{ zeolit sintesis dengan air laut } \\
\cline { 2 - 4 } & Suhu & Suhu & Suhu \\
& $35^{\circ} \mathrm{C}$ & $45^{\circ} \mathrm{C}$ & $60^{\circ} \mathrm{C}$ \\
\hline $\mathrm{O}$ & $49,8 \%$ & $41,5 \%$ & $50,1 \%$ \\
$\mathrm{Na}$ & $26,8 \%$ & $28,1 \%$ & $24,3 \%$ \\
$\mathrm{Si}$ & $6,9 \%$ & $11,6 \%$ & $7,6 \%$ \\
$\mathrm{~A} 1$ & $5,6 \%$ & $10,5 \%$ & $6,9 \%$ \\
$\mathrm{~N}$ & $4,7 \%$ & $3,6 \%$ & $5,0 \%$ \\
$\mathrm{C}$ & $2,5 \%$ & $2,6 \%$ & $3,4 \%$ \\
$\mathrm{~K}$ & $2,0 \%$ & - & - \\
$\mathrm{Cl}$ & $1,6 \%$ & $2,0 \%$ & $2,7 \%$ \\
\hline
\end{tabular}

Dari data EDX di atas dapat melihat jumlah unsur yang terkandung dalam senyawa yang dihasilkan, jumlah unsurnya dinyatakan dalam persen berat. Dari tabel 2 dapat terlihat bahwa komposisi dari senyawa yang terbentuk dan distribusi dari unsur-unsur yang ada dalam sampel yang telah disintesis. Berdasarkan dari tabel diatas terlihat terdapat unsur $\mathrm{Cl}$ yang merupakan bagian unsur yang menyusun senyawa sodalit dimana rusmus kimia dari sodalit itu sendiri adalah $\mathrm{Na}_{8}\left(\mathrm{Al}_{6} \mathrm{Si}_{6} \mathrm{O}_{24}\right) \mathrm{Cl}_{2}$.

\section{KESIMPULAN}

Zeolit dapat disintesis dari fly ash batubara Ombilin yang dilebur dengan $\mathrm{NaOH}$ pada suhu $550^{\circ} \mathrm{C}$ menggunakan air laut untuk kristalisasi pada suhu rendah yaitu pada suhu $35^{\circ} \mathrm{C}, 45{ }^{\circ} \mathrm{C}$, dan $60{ }^{\circ} \mathrm{C}$. Hasil zeolit yang terbentuk dari sintesis zeolit menggunakan air laut dalam proses alkali hidrotermal dan untuk kristalisasi cukup baik, karena tidak terdapat lagi $\mathrm{SiO}_{2}$ (quartz). Suhu terbentuknya zeolit dengan struktur kristal yang lebih baik terjadi pada suhu $60^{\circ} \mathrm{C}$. Sintesis zeolit pada suhu rendah dengan menggunakan air laut menghasilkan tipe zeolit berupa sodalit yang merupakan kerangka dari zeolit tipe $\mathrm{X}$.

\section{DAFTAR PUSTAKA}

1. Sunardi.,Abdullah (2007) "Conversion of Coal Fly Ash Into Zeolite and its Aplication for Mercury(II) Adsorbent" Sains dan Terapan Kimia, vol.1, no.1, hal 1-10

2. Prijatama, Herry. Eko Tri Sumarnadi. (1996). "Pemanfaatan Limbah Abu Batubara PLTU."Prosiding Pemaparan Hasil Litbang Ilmu Pengetahuan Teknik

3. Wustoni, Shofarul. Rino.R. Mukti, dkk. (2011). "Sintesis Zeolit Mordenit dengan Bantuan Benih Mineral Alam Indonesia." Jurnal Matematika \& Sains, Desember 2011, Vol. 16 Nomor 3

4. Fuoco, Domenico.,(2012). "A New Method for Characterization of Natural Zeolites and Organic Nanostructure Using Atomic Force Microscopy. "Journal Nanomaterials , 2, 79-91;doi:10.3390/nano2010079

5. Xu, Ruren., Wenqin Pang., Jihong yu., Qisheng Huo., Jiesheng Chen.(2007). "Chemistry of Zeolites and Related Porous Materials: Synthesis and Structure. "John Wiley and Sons Asia Singapore 
6. Taarning ,Esben., Christian M. Osmundsen., Xiaobo Yang., Bodil Voss., Simon I. Andersen., and Claus H. Christensen. (2010). "Zeolite-catalyzed biomass conversion to fuels and chemicals "Energy and Environmental Science Accepted 1st October 2010

7. Saputra, Rodhie. (2006). "Pemanfaatan Zeolit Sintesis sebagai Alternatif Pengolahan Limbah Industri.

8. Yuanita Lestari, Dewi. (2010). "Kajian Modifikasi dan Karakterisasi Zeolit Alam dari Berbagai Negara." Jurdik Kimia UNY.

9. Sutarno. Yaterman Arryanto, dkk. (2004). "Sintesis Faujasit dari Abu
Layang Batubara: Pengaruh Refluks dan Penggerusan Abu layang Batubara terhadap Krirtalinitas Faujasit”. Jurnal Matematika dan Sains Vol. 9 No. 3, September 2004, hal 285-290.

10. characterization of Hydroxyapatite Nanorods Under Hydrotermal Condition. Journal of Materials Scienc . 2009, 27, 961-971.

11. B. Liu and H.C. Zeng, Hydrothermal Synthesis of ZnONanorods in Diameter Regime of $50 \mathrm{~nm}$. Journal of the American Chemical Society, 2003, 125, 4430-4431. 